\title{
Cartografia dos trabalhos publicados no ENPEC acerca do Ensino de Ciências para os sujeitos com Espectro Autista
}

\section{The Cartography of the ENPEC published works about Science Teaching for students with the Autistic Spectrum}

\author{
Sandra Elisabet Bazana Nonenmacher (sandraebn1964@gmail.com) \\ (Instituto Federal Farroupilha)
}

Cátia Keske (catia.keske@iffarroupilha.edu.br)

(Instituto Federal Farroupilha- Campus Panambi)

Daniela Carolina Ernst (daniela.ernst@ufrgs.br)

(Universidade da Fronteira Sul- Campus Cerro largo)

Sirlei Rigodanzo (sirlei.rigodanzo@iffarroupilha.edu.br)

(Instituto Federal Farroupilha- Campus Panambi)

Resumo: Esta pesquisa qualitativa faz uso da cartografia, aqui entendida enquanto diferente léxico deleuziano e guattariano, operada como possibilidade metodológica, investigativa e intervencionista desenvolvida como um plano de pensamento para operacionalizar as investigações realizadas em anais de evento de todas as edições do Encontro Nacional de Pesquisa em Educação em Ciências (ENPEC), tendo como descritores a palavra Autismo ou TEA (Transtorno do Espectro Autista). A temática de pesquisa foi definida pela necessidade de incorporar, no Ensino de Ciências, reflexões e possibilidades de diferentes metodologias que contemplem a premissa da inclusão, nos seus diferentes âmbitos. Como as estatísticas apontam um número significativo de crianças com TEA no Brasil, este foi o foco delimitado neste artigo. O mapeamento realizado apontou somente três trabalhos que, apesar de contemplarem metodologias e conteúdos distintos de Ciências, se aproximam pelo uso de recursos visuais e interativos. Dessa maneira, identificamos com preocupação o reduzido número de trabalhos que abordam esse tema e apontamos a urgência de novas pesquisas na área, justamente num momento histórico de alteração na legislação pertinente a Educação Inclusiva.

Palavras-chave: TEA, Educação Inclusiva, Metodologias.

Abstract: This qualitative research makes use of the cartography, understood and applied here as a Deleuze and Guattari lexicon, operated as a methodological, investigative and interventionist possibility. as a thought plan to operationalize the investigations carried out in the annals of events of all editions of the National Research Meeting in Science Education (ENPEC), using the word Autism or ASD (Autistic Spectrum Disorder) as descriptors. The choice of the research theme was defined by the need to incorporate, in Science Education, reflections and methodologies that contemplate the premise of 
inclusion, in its different spheres. As the statistics indicate a significant number of children with ASD in Brazil, this was the focus outlined in this article. The mapping showed only three works that, despite contemplating methodologies and different contents of Sciences, are approached by the use of visual and interactive resources. Thus, we identified with concern the small number of works that address this importante theme and pointed out the urgency of new research in the area. Specifically at this historic moment of change in the legislation related to Inclusive Education.

Keywords: TEA, Inclusive Education, Methodologies.

\section{INTRODUÇÃO}

O conceito de inclusão perpassa uma heterogeneidade de significações, concepções e aspectos. Muitos se apropriam e se utilizam do termo sem que, contudo, tenham entendido seus significados. Dessa maneira, apropriamo-nos da fala de Sassaki (1997, p. 41), que apresenta a inclusão como “o processo pelo qual a sociedade se adapta para poder incluir em seus sintomas sociais gerais, pessoas com necessidades especiais e, simultaneamente, estas se preparam para assumir seus papéis na sociedade". De acordo com Mantoan (2005, p. 24), a inclusão pode ser definida como "a nossa capacidade de entender e reconhecer o outro e, assim, ter o privilégio de conviver e compartilhar com pessoas diferentes de nós”. Segundo o Manual Estatístico de Diagnóstico e Transtornos Mentais (DSM-V), o Transtorno do Espectro Autista (TEA) pode ser caracterizado por prejuízos na comunicação e por comportamentos estereotipados e repetitivos. Estes prejuízos incluem déficits na comunicação, na interação social em múltiplos contextos, na reciprocidade social, em comportamentos não-verbais de comunicação usados para interação social e em habilidades para desenvolver, manter e compreender relacionamentos. Além destas características, um sujeito com TEA pode apresentar outras comorbidades, como, por exemplo, a seletividade alimentar (MARI-BASET et al, 2014) que, em nossa compreensão, pode ser explorada por meio da abordagem de conceitos científicos no contexto educativo da Educação Básica. Para Gonçalves, Kauark e Nunes Filho:

[...] o universo do autismo é uma realidade complexa, que engloba conceitos distintos, mas que se entrelaçam em determinados pontos. A evolução que se tem verificado ao longo do tempo relativamente à sua terminologia tem convergido para um melhor esclarecimento da síndrome autista, embora seja necessário ter em conta que as características identificadas não estão presentes 
Se há polifonia quanto ao termo inclusão no contexto educativo, também há quanto a autismo. Segundo Stepanha (2017, p. 146), um dos principais obstáculos aos processos inclusivos de alunos com TEA é a falta de compreensão do conceito do Autismo, o que implica a reprodução de metodologias que contribuem para o desenvolvimento de atraso cognitivo. Em seu estudo, a autora problematiza pesquisas centradas na deficiência e/ou déficit que concebem as características autísticas como impedimento para a aprendizagem, desconsiderando os aspectos socioculturais fundamentais para o desenvolvimento humano.

Alerta, assim, para a importância de considerarmos o contexto histórico-cultural e o processo de humanização dos sujeitos, em especial, de que "todos podemos aprender desde que se estabeleçam processos de mediação adequados às nossas condições biológicas, psicológicas e sociais." (STEPANHA, 2017, p. 146).

Um trabalho pedagógico e a atividade docente dessa perspectiva, não podem, entretanto, ficar no plano discursivo de documentos oficiais das escolas e legislações vigentes. Contudo, conhecer e tensionar mudanças e alargamentos conceituais, bem como ampliação de políticas públicas e direitos aos sujeitos com TEA, pode, em nosso ponto de vista, contribuir para a apropriação do conhecimento, inserção social e permanência deles na escola.

No Brasil, a Política Nacional de Proteção dos Direitos da Pessoa com Transtorno do Espectro do Autismo, criada pela Lei $n^{\circ}$ 12.764/2012, consolidou um conjunto de direitos a esses sujeitos, cabendo à escola e à comunidade escolar assumirem a perspectiva da educação inclusiva. Sendo esta uma política voltada ao TEA, vale destacar que as concepções que subsidiam seu conteúdo atende a uma premissa estabelecida anteriormente pela Política Nacional de Educação Especial na Perspectiva da Educação Inclusiva (PNEEPEI): “acompanhar os avanços do conhecimento e das lutas sociais, visando constituir políticas públicas promotoras de uma educação de qualidade para todos os estudantes" (BRASIL, 2008). 
Marco do reconhecimento da educação inclusiva como balizadora da Educação Especial, a PNEEPEI, já em sua introdução, anunciava:

\begin{abstract}
O movimento mundial pela educação inclusiva é uma ação política, cultural, social e pedagógica, desencadeada em defesa do direito de todos os estudantes de estarem juntos, aprendendo e participando, sem nenhum tipo de discriminação. A educação inclusiva constitui um paradigma educacional fundamentado na concepção de direitos humanos, que conjuga igualdade e diferença como valores indissociáveis, e que avança em relação à idéia de eqüidade formal ao contextualizar as circunstâncias históricas da produção da exclusão dentro e fora da escola. (BRASIL, 2008, p. 1).
\end{abstract}

Ao encontro do paradigma educacional defendido pela PNEEPEI, a Lei $\mathrm{n}^{\circ}$ 12.764/2012 define a obrigatoriedade da inserção de sujeitos com TEA nas escolas regulares estabelecida, vedando a recusa de matrícula a pessoas com qualquer tipo de deficiência e estabelecendo punição para o gestor escolar ou autoridade competente que praticasse ato discriminatório dessa natureza (BRASIL, 2012).

Embora não seja retirado, o direito ao acesso e à permanência nas classes comuns das escolas de Educação Básica, ficou recentemente "comprometido" pelo Decreto $\mathrm{n}^{\mathrm{o}}$ 10502/2020 (BRASIL, 2020) que, ao instituir a Política Nacional de Educação Especial: Equitativa, Inclusiva e com Aprendizado ao Longo da Vida, retoma perspectivas que permitem a separação entre sujeitos e grupos. Dentre as notas de repúdio ao previsto neste texto legal, a Associação Brasileira de Saúde Coletiva (ABRASCO) evidencia que o conteúdo desta Política ratifica perspectivas superadas nos estudos sobre educação inclusiva e na legislação internacional que a ampara, incluindo os tratados internacionais dos quais o Brasil é signatário, defendendo que o caminho não é alterar a política de inclusão vigente no sentido de retrocedê-la, mas compreender tecnicamente como transformar os problemas em oportunidades, aprendizados e afirmação da inclusão. (ABRASCO, 2020).

O Grupo de Trabalho Educação Especial GT 15, da Associação Nacional de PósGraduação e Pesquisa em Educação (ANPED), também em postura de repúdio ao Decreto 10.502/2020, chama a atenção para o fato de que, nas últimas décadas, os estudos sobre aprendizagem, desenvolvimento humano e práticas pedagógicas evidenciam questões históricas, culturais e sociais como determinantes para prejuízos à apropriação dos conhecimentos por estudantes com deficiência e não questões orgânicas, genéticas e de desestrutura familiar - justificativa de governos, profissionais da educação e de áreas afins 
para promover a separação, a discriminação e o preconceito contra esses estudantes. A defesa do GT 15 pauta-se, ainda, na ideia que a matrícula desses estudantes nas escolas de educação básica comuns foi

fundamental para colocá-los na pauta da discussão das políticas educacionais,
alavancar os seus processos de aprendizagem e escolarização, promover
práticas pedagógicas direcionadas às suas demandas e realizar, especialmente
nos âmbitos municipais e estaduais, políticas de formação continuada de
profissionais da educação inclinadas a esse propósito. (GT 15 ANPED, 2021).

(Des) Caminhos como esse, não são, contudo, novidade no contexto educativo, especialmente, de pessoas com deficiência. Segundo Baptista (2019),

no contexto brasileiro, podemos afirmar que os últimos cinquenta anos produziram mudanças que, a depender do ângulo de elaboração da análise, parecem evocar grandes rupturas com as práticas instituídas ou mostrar que, apesar de alterações superficiais, o que existe é a continuidade dos habituais modos de conceber a pessoa com deficiência e de propor, para esses sujeitos, percursos educacionais que são essencialmente os mesmos que eram oferecidos em décadas anteriores. (BAPTISTA, 2019, p. 2)

Este compromisso inclusivo, que cabe à escola nos planos normativos, estende-se, consequentemente, a todos os profissionais que nela atuam, inclusive aos professores da área de Ciências da natureza, premissa que conduz à questão que desencadeou esta pesquisa: Como profissionais da área, estamos produzindo algum conhecimento sobre o ensino de Ciências e Autismo?

Gonçalves, Kauark e Nunes Filho (2020) enfatizam que o professor de Ciências necessita, ao desenvolver suas atividades com estudantes com espectro autista, do apoio de profissionais especializados e da família no sentido de identificar quais as melhores adaptações e metodologias mais eficazes. Shaw (2021) investigou possíveis contribuições de familiares, educadores e terapeutas no desenvolvimento de indivíduos com TEA, a partir de uma revisão integrativa da literatura. A autora indica que a aquisição de conhecimentos, a colaboração mútua e o enfrentamento de desafios da condição são possíveis caminhos e podem auxiliar no desenvolvimento de pessoas com espectro autista.

Porém, além da falta de uma formação que possibilite a aquisição de conhecimentos, nem sempre esta parceria acontece, como, por exemplo, o artigo de Costa e Medeiros (2020) descreve uma prática pedagógica sobre animais selvagens, elaborada 
por uma estudante de um curso de Licenciatura de Ciências Biológica, desenvolvida em uma turma do segundo ano do Ensino Fundamental na qual havia dois estudantes com necessidades educacionais especiais (NEE), sendo um com TEA, mas que não contava com nenhum auxiliar (monitor) em sala de aula nem junto à professora para a elaboração e adaptação das atividades de ensino.

Apesar da importância do tema e a necessidade de estudos, a inclusão de estudantes com necessidades educacionais especiais é um tema recente em pesquisas sobre o ensino de Ciências brasileiro (BASSO; CAMPOS, 2019). Fato confirmado, também, nesta pesquisa, como o leitor poderá acompanhar na sequência deste artigo.

Nossos objetivos se materializam na direção de investigar diferentes possibilidades de desenvolvimento de ações pedagógicas mais inclusivas em Ciências da natureza, em salas de aula regulares. Almejamos, para tanto, apontar a relevância do ensino de Ciências na direção de auxílio à compreensão de alguns conceitos científicos básicos que podem melhorar a qualidade de vida de pessoas com espectro autista a partir de investigações diagnósticas.

O interesse pelo tema: o compromisso com a inclusão e a aprendizagem de conceitos científicos no contexto escolar, instigou-nos a fazer um mapeamento dos trabalhos desta natureza publicados em anais do Encontro Nacional de Pesquisa em Educação em Ciências (ENPEC). O intuito foi o de localizar artigos que apresentam e discutem práticas de ensino inclusivas aos sujeitos com TEA e quais conceitos são explorados, publicados entre os anos 1997 a 2019, objetivando, desta forma, aproximarmo-nos de maiores compreensões à questão central.

\section{METODOLOGIA}

Esta pesquisa qualitativa faz uso da cartografia e do diferente léxico Deleuze Guattariano, aqui operada como potência investigativa, aliada à prática investigativa intervencionista desenvolvida por Guattari como um plano de pensamento, ao deparar-se com o trabalho desenvolvido pelo pedagogo Fernand Deligny (1913-1996) que cartografou as crianças autistas em Cévennes, uma região rural localizada no sul da 
França. Na ocasião, deu-se início aos estudos sobre autismo e foi o ápice da luta antimanicomial.

Deligny (2013) propõe a seus estagiários que tracem, acompanhem, observem os deslocamentos dessas crianças pelo terreno da propriedade, que acompanhem seus interesses e como poderiam ser acompanhados por meio de registros, dessas errâncias, acontecimentos, gestos, e o desenvolvimento de alguma atividade específica.

A cartografia, entendida a partir desse referencial, contribui como possibilidade que cria novos conceitos que "ultrapassam as dualidades historicamente estabelecidas e, ao mesmo tempo, dão às coisas uma verdade nova, uma distribuição nova, um recorte extraordinário" (DELEUZE, 1999, p. 125). Para pensar a imagem da pesquisa, alguma dobra cartográfica se faz presente. Dessa maneira, também buscamos pistas de operacionalização nos Volumes I, III e IV de Mil Platôs: Capitalismo e esquizofrenia, publicados no Brasil nos anos 90.

A partir dessas imersões históricas, e a visita às obras que a mencionam e possibilitam o seu deslocamento e plasticidade para sua operacionalização, foram investigados os anais de todas as edições do Encontro Nacional de Pesquisa em Educação em Ciências (ENPEC), evento bienal promovido pela Associação Brasileira de Pesquisa em Educação em Ciências (ABRAPEC), que teve sua primeira edição em 1997 e a última, a décima segunda, em 2019.

A escolha do evento justifica-se por sua relevância no contexto de socialização e discussão de pesquisas na área de Ciências realizadas por professores da Educação Básica e do Ensino Superior, estudantes e professores de cursos de licenciatura e de pósgraduação, pesquisadores das áreas de Educação em Ciências Biológicas, Física, Química e áreas correlatas. É um evento que inicia com o primeiro Encontro, em novembro de 1997, quando é criada, de forma concomitante ao evento, a ABRAPEC. Esta Associação conta atualmente com mais de mil sócios (ABRAPEC, 2021) e desempenha um papel importante nas pesquisas em Educação em Ciências, convergindo pesquisadores brasileiros e internacionais. 
Para operacionalizar as investigações foram acessados os anais de todos os ENPEC disponíveis no site da ABRAPEC (http://abrapecnet.org.br/) com a busca dos descritores Autismo e TEA (Transtorno do Espectro Autista).

O mapeamento identificou três trabalhos cujas informações foram organizadas em formato de Quadro-Síntese, contendo título, ano de publicação, autores e instituições de Ensino Superior aos quais o estudo e/ou os autores estão vinculados.

Quadro 1 - Quadro-Síntese dos trabalhos encontrados

\begin{tabular}{|c|c|c|}
\hline Trabalhos & Autores & Instituição \\
\hline $\begin{array}{l}\text { Contribuições da Semiótica } \\
\text { para a Inclusão de } \\
\text { Estudantes Autistas no } \\
\text { Ensino de Ciências } \\
\text { (2015) }\end{array}$ & $\begin{array}{c}\text { José Antônio Casais Casais } \\
\text { Waldmir Araujo Neto }\end{array}$ & $\begin{array}{c}\text { Universidade Federal do Rio de } \\
\text { Janeiro/Programa de Pós-Graduação em } \\
\text { Ensino de Química - PEQui Laboratório de } \\
\text { Estudos em Semiótica e Educação Química - } \\
\text { Leseq }\end{array}$ \\
\hline $\begin{array}{c}\text { Ensino de Ciências } \\
\text { inclusivo para alunos com } \\
\text { Transtorno do Espectro } \\
\text { Autista e o uso de } \\
\text { Sequências Didáticas } \\
\text { (2017) }\end{array}$ & $\begin{array}{l}\text { Marcella Fernandes Xavier } \\
\text { Bruno Yuri } \\
\text { Diogo Silva } \\
\text { Paloma Alinne Alvares } \\
\text { Rodrigues }\end{array}$ & $\begin{array}{l}\text { Núcleo de Estudos em Formação Docente, } \\
\text { Tecnologia e Inclusão - NEFTI, da } \\
\text { Universidade Federal de Itajubá (UNIFEI) }\end{array}$ \\
\hline $\begin{array}{l}\text { Gamificação: uma } \\
\text { estratégia para socializar o } \\
\text { aluno autista de grau leve } \\
\text { nas aulas de ciências } \\
\text { (2019) }\end{array}$ & $\begin{array}{l}\text { William da Silva Costa } \\
\text { Betânia Viana } \\
\text { Luan Sidonio Gomes }\end{array}$ & $\begin{array}{l}\text { Universidade do Estado do Pará } \\
\text { Universidade Federal do Pará }\end{array}$ \\
\hline
\end{tabular}

Fonte: As Autoras (2020)

Os três artigos foram lidos na íntegra buscando-se identificar, neles, as questões de pesquisa, metodologia utilizada, público alvo e alguns de seus resultados. Na sequência deste artigo são apresentados alguns destes dados.

\section{RESULTADOS E DISCUSSÕES}

Em relação aos trabalhos identificados, estes foram organizados por data de publicação: X ENPEC em 2015, XI ENPEC de 2017 e o XII ENPEC de 2019 (Quadro 1). Como podemos perceber, além de estarem restritos aos três últimos encontros do 
ENPEC, apenas um trabalho sobre a temática foi apresentado/selecionado por edição do evento, o que denota uma contemporaneidade da temática na Educação em Ciências e o pequeno espaço a ela reservado no Brasil, mesmo diante da estimativa de 2 milhões de pessoas com espectro autista no País (PASSOS-BUENO; VADAZS; HUBNER, 2015). Cabe destacar que isto não significa que não existam artigos relacionando Educação em Ciências e Inclusão no ENPEC. O artigo de Santos e Galieta (2019), disponível nos anais do próprio evento (XII ENPEC), afirma que nas onze edições anteriores do evento foram apresentados 8.183 trabalhos, dos quais 119 tinham relação com educação inclusiva. Segundo estes autores, apesar do número de trabalhos sobre educação inclusiva ter apresentado um crescimento no evento ao longo de suas edições, este número ainda é considerado insuficiente diante da repercussão da temática e por suas diversas áreas de abrangência.

Os três trabalhos localizados foram produzidos por pesquisadores ligados a Universidades Federais Brasileiras das regiões Sudeste e Norte do País. Apresentam relatos e resultados de pesquisas desenvolvidas em escolas de educação básica que envolvem práticas pedagógicas e metodológicas. Ao mesmo tempo, destacam o compromisso da educação e, acrescentamos, do Ensino de Ciências com os estudantes incluídos e a inserção desta temática na formação inicial e continuada de professores.

Casais e Neto (2015) apresentam uma sequência de episódios verbais analisados quando estudantes do sétimo ano do Ensino Fundamental, numa turma com 32 alunos sendo uma autista incluída, assistem a um documentário e a professora vai fazendo questionamentos acerca de características morfológicas de insetos que aparecem no vídeo.

Tendo como referencial teórico a perspectiva sociocultural vigotskiana das interações discursivas, o professor da turma inicia ou delimita os momentos de interação verbal da atividade. Baseados em Araujo Neto (2009), os pesquisadores utilizam um mapa de eventos como ferramenta metodológica.

Dessa forma, sustentam que "o repertório teórico da Semiótica é abrangente e pode oferecer alternativas e suportes teóricos para atividades com alunos autistas, não somente em termos do uso de filmes/vídeos." (CASAIS; NETO, 2015, p. 6). Este trabalho 
evidencia, também, o potencial do visual, diante das limitações verbais e da coerência central $^{1}$ de pessoas com TEA.

No artigo de Xavier, Silva e Rodrigues (2017) apresenta-se a potencialidade da sequência didática "Misturando com Buzz e seus amigos", para ensinar de forma dinâmica e demonstrativa os estados físicos da matéria e as classificações de misturas para um estudante com espectro autista do primeiro ano do Ensino Fundamental da Educação Básica.

Destaca-se, neste trabalho, o uso de recursos visuais (imagens e esquemas), assim como no trabalho de Casais e Neto (2015), e de materiais de manipulação. Esta atividade foi elaborada e desenvolvida por estudantes de licenciatura; para acompanhar e registrar os dados, foi utilizada a técnica da observação participante (GERHARDT; SILVEIRA, 2009).

Os resultados foram apresentados sob uma ótica de análise. Neste sentido, o potencial inclusivo do trabalho deve-se, além da inserção da temática na formação inicial de professores, à possibilidade de perceber que crianças com espectro autista também possuem capacidade cognitiva para aprender conceitos científicos, além da inserção de conceitos químicos desde as séries iniciais.

Costa, Viana e Gomes (2019), em uma pesquisa qualitativa, discutem sobre a gamificação ${ }^{2}$ como elemento potencial para auxiliar na aprendizagem e socialização entre estudantes de uma turma do segundo ano do Ensino Fundamental de uma escola pública de Educação Básica. Nesta turma encontrava-se incluído um estudante com espectro autista de grau leve ${ }^{3}$. O jogo teve enfoque no tema água e educação ambiental.

\footnotetext{
${ }^{1}$ Dificuldade do sujeito no espectro autista de integrar partes para a compreensão de um todo. A tendência é que o autista visualize as várias partes não integradas. (LACERDA, 2018).

${ }^{2}$ Gamification, termo em inglês utilizado pela primeira vez em 2002, por Nick Pelling. Segundo Carolei e Tori (2014), a gamificação incorpora elementos de diversos jogos em processos diferentes. Para Tolomei (2017), gamificação consiste na utilização de elementos dos games - tais como estratégias, pensamentos e problematizações - fora do contexto de games, com o intuito de promover a aprendizagem, motivando os indivíduos a alguma ação e auxiliando na solução de problemas e interação com outros indivíduos (Kapp, 2012).

${ }^{3}$ Segundo o DSM - V1 (2014), o autismo é subdividido em três graus: leve, moderado e grave, distintos pelo grau de comprometimento das funções sociais, comportamentais e linguísticas do indivíduo acometido.
} 
Foi organizado em cinco etapas com níveis de dificuldades distintos, envolvendo conceitos relacionados aos estados físicos da água, características da água no ambiente e sua importância para a vida, entre outros. As atividades foram desenvolvidas em grupo e com o uso de imagens, desenhos, gravuras e cruzadinha a partir de palavras destacadas em um texto sobre a água. Seus resultados apontam a interação do estudante com espectro autista no grupo potencializada pelo uso de recursos visuais que desencadearam as conversas entre eles.

Com abrangências e formas distintas, os três trabalhos provocam pensar sobre quais estratégias metodológicas podem auxiliar os processos de ensino e aprendizagem de Ciências de sujeitos com autismo, algo que Resende defende: "o que guia não é a adequação a um padrão de normalidade e de produção, mas o engajamento recíproco em torno de algo"(2016, p.84). Ferdinand Deligny compreende o sujeito docente, sobretudo, como criador e facilitador de circunstâncias e a educação entendida por ele implica na criação de um "[...] espaço onde o outro pode crescer, equivocar-se, sonhar, recusar, escolher. Educar não é submeter, mas sim permitir. Não é ser modelo, mas sim referente. Não é uma lição, mas sim um encontro. Educar não é fechar, é abrir” (DELIGNY, 1977 apud PLANELLA, 2012, p. 107, tradução nossa).

Nesta provocação, outra: Em um mundo altamente tecnológico, como as ferramentas digitais podem vir a ser utilizadas? E, por fim, outra: como a diferença é compreendida neste contexto educativo, onde sujeitos com espectro autista têm o direito ao conhecimento?

Para Ravet (2017), os cursos de formação inicial de professores visam a preparar futuros professores introduzindo atividades ou componentes curriculares de prática profissional em universidades em todo o planeta. Legislações, incluindo do Reino Unido, onde a pesquisa foi realizada e do Brasil, no caso deste artigo, indicam que durante a formação, os futuros professores devem ser preparados para atender às necessidades de todas as crianças em salas de aula regulares, incluindo alunos com espectro autista. Mas será que na prática essa demanda é suprida durante a formação? Na maioria das vezes, atender a legislação se resume à inclusão de um componente curricular de Libras na licenciatura. Em uma análise do estado do conhecimento sobre TEA e educação, Stepanha 
(2017) evidencia que ainda faltam aos professores formação específica na área, e uma melhor compreensão teórica sobre o desenvolvimento humano e sobre o Autismo.

Conclusões da pesquisa desenvolvida por Ravet (2017), indicam que a maioria dos licenciandos e professores tinham alguma consciência básica do autismo, mas pouco ou nenhum conhecimento e compreensão das estratégias de ensino para crianças com TEA, por lacunas na formação. Além disso, foi consenso de que, para garantir a inclusão de alunos com autismo nas salas de aula regulares, as lacunas a serem superadas estão relacionadas à falta de experiência dos professores formadores e professores em exercício nas escolas, excesso de preocupações com a rotulagem médica ou falta de diagnósticos e questões sobre a sobrecarga e as prioridades do currículo durante a formação inicial e em desenvolvimento nas escolas de Educação Básica.

Stepanha (2017, p. 146) sugere que a formação docente paute-se pela premissa de "ir além dos limites intelectuais e/ou sensoriais impostos pela deficiência, para que o aparato biológico humano crie outros dispositivos de reorganização cultural e assim o aluno se aproprie do legado historicamente produzido". Para ela, "a apropriação do conhecimento efetivar-se-á de maneira plena a partir da docência que possibilite ao aluno, ser social em pleno desenvolvimento, o acesso ao conhecimento científico em sua forma mais elaborada" (2017, p. 146).

A realidade, apresentada pelos dados da pesquisa desta autora, evidencia que professores não precisam depender de laudos médicos (indicativos de um CID e da necessidade de atendimento em Sala de Recursos Multifuncional e Atendimento Educacional Especializado) para iniciar o trabalho pedagógico com alunos com necessidades educacionais especiais. Não excluindo a importância destes laudos e da parceria entre os professores e os educadores especiais, cabe ao docente a responsabilidade de, no mínimo, conhecer o aluno e qual sua deficiência para que os encaminhamentos pedagógicos venham ao encontro das suas necessidades; cabe a ele conhecer o que e porque ensinar, subsidiado por um referencial teórico que fundamente sua prática pedagógica.

Em perspectiva deleuzeana, Medeiros (2012) amplia nossa compreensão ao defender a possibilidade de um sujeito com deficiência "conhecer, reconhecer, aceitar seu corpo e suas diferenças, não como deficiências ou inferioridades, mas como algo que lhe 
é próprio somente seu unívoco" (MEDEIROS, 2020, p. 65). Consegue assim compreender o professor de Ciências da Natureza? O desafio talvez seja compreender a premissa de Deleuze quanto à univocidade, na qual, “já parece que não são as diferenças que são e têm de ser. O ser é que é Diferença, no sentido em que ele se diz da diferença" (DELEUZE, 2006 apud MEDEIROS, 2012, p. 65). Um sujeito com TEA, se diz, se dirá da diferença, o que exige sensibilidade docente que lhe permita a recusa de uma representação generalizada da diferença que o leve ao descaminho da negação.

\section{CONCLUSÃO}

A pesquisa pode, num primeiro momento, ser considerada irrelevante diante do pequeno número de artigos mapeados no ENPEC, porém, para nós o mérito dela também reside nisso. Por que temos um quantitativo de apenas três trabalhos num universo de quase 10.000 trabalhos num dos eventos mais representativos da Educação em Ciências no País, sendo que temos uma estimativa de 2 milhões de autistas no Brasil?

Parece ser consenso, a partir da análise dos trabalhos, que práticas ou metodologias que sejam pautadas pelo uso de recursos visuais são promissoras no ensino com autistas ou, pelo menos, foram os recursos usados nos três trabalhos e apresentaram resultados satisfatórios. Quanto aos conceitos científicos explorados, parece-nos frágil fazer alguma consideração, a não ser talvez que a escolha deva ser daqueles que possuem maior aproximação com o cotidiano dos estudantes, fato este que se adequa, também, a estudantes neurotípicos.

Parece-nos imprescindível apontar, ainda, a necessidade de ampliar o número de pesquisas que envolvam e descrevem práticas pedagógicas no ensino de Ciências com estudantes autistas e que elas sejam socializadas nos diferentes espaços de sistematização e produção de conhecimento. Seja em eventos acadêmico-científicos, periódicos científicos ou cursos de formação inicial e continuada de professores, urge ampliarmos a produção escrita e, assim, rizomatizar a temática em toda a comunidade educacional, sem deixar de considerar a polifonia conceitual que a constitui. De acordo com Baron-Cohen e Belmonte (2005), sujeitos autistas podem apresentar talentos incomuns para a 
sistematização, o que indica que esses sujeitos podem construir conhecimento a partir das sistematizações.

\begin{abstract}
Descobrimos que as pessoas com autismo ou Síndrome de Asperger podem ter talentos incomuns na sistematização (por exemplo, na física), [...] que mesmo entre o baixo funcionamento, indivíduos com autismo clássico, interesses mesquinhos 'obsessivos' tendem a se concentrar em sistemas, e que seu comportamento excessivamente repetitivo e interesse podem ser sinais de forte sistematização (BARON-COHEN; BELMONTE, 2005, p.109-260, tradução nossa).
\end{abstract}

A questão que estimulou esta pesquisa, contudo, ainda carece de muitas respostas e suscita outras perguntas, dentre as possibilidades destacamos duas: como e qual ciências ensinar para pessoas que pensam, interagem e visualizam o mundo de forma diferente? Quiçá, ou melhor, "tomara" que tanto nós quanto outros profissionais e estudantes envolvidos nos processos de inclusão, bem como no ensino de Ciências para autistas, possamos voltar a elas.

\title{
5. REFERÊNCIAS
}

ABRAPEC. Associação Brasileira de Pesquisa em Educação em Ciências. Disponível em: http://abrapecnet.org.br/wordpress/pt/sobreaabrapec. Acesso em1sd: 15 de janeiro de 2021.

ABRASCO. Nota de repúdio ao Decreto ${ }^{\circ}$ 10.502, de 30 de setembro de 2020, que institui a Política Nacional de Educação Especial. Disponível em:

https://www.abrasco.org.br/site/noticias/nota-de-repudio-ao-decreto-no-10-502-de-30de-setembro-de-2020-que-institui-a-politica-nacional-de-educacao-especial/52894/. Acesso em: 06 jan. 2021.

ANPED. Manifestação do Grupo de Trabalho em Educação Especial GT 15 da Associação Nacional de Pós-Graduação e Pesquisa em Educação (ANPED). Disponível em: https://anped.org.br/news/manifestacao-do-gt-15-de-repudio-declaracao-dopresidente-da-republica-sobre-pessoas-com. Acesso em: 15 jan. 2021.

ARAUJO NETO, W. N. Formas de uso da noção de representação estrutural no ensino superior de Química. 2009. Tese (Doutorado em Educação) - Faculdade de Educação, Universidade de São Paulo, São Paulo, 2009.

BAPTISTA, C. R. Política pública, Educação Especial e escolarização no Brasil. Educação e Pesquisa, Revista da Faculdade de Educação da USP, São Paulo, v. 45, e217423, 2019. 
BARON-COHEN, S.; BELMONTE, M. K. Autism: a window onto the development of the social and the analytic brain. Annual review of neuroscience, v. 28, p. 109-260, 2005 .

BASSO, S. P. S.; CAMPOS, L. M. L. Licenciaturas em ciências e educação inclusiva: a visão dos/as licenciandos/as. Revista Eletrônica de Educação, v. 3, n. 2, p. 554-571, maio-ago 2019. Disponível em:

http://www.reveduc.ufscar.br/index.php/reveduc/article/view/2522. Acesso em: 5 de janeiro de 2021.

BRASIL. Política Nacional de Educação Especial na perspectiva da educação inclusiva. Brasília, DF: MEC/ SEESP, 2008. Disponível em:

http://portal.mec.gov.br/arquivos/pdf/politicaeducespecial.pdf. Acesso em: 17 set. 2020.

BRASIL. Lei $n^{\circ}$ 12.764, de 27 de dezembro de 2012. Institui a Política Nacional de Proteção dos Direitos da Pessoa com Transtorno do Espectro do Autismo; e altera o $\S 3^{\circ}$ do art. 98 da Lei $\mathrm{n}^{\circ}$ 8.112, de 11 de dezembro de 1990. Disponível em:

https://www2.camara.leg.br/legin/fed/lei/2012/lei-12764-27-dezembro-2012-774838publicacaooriginal-138466-pl.html. Acesso em: 05 jan. 2021.

BRASIL. Decreto ${ }^{\circ} 10.502$, de 30 de setembro de 2020. Institui a Política Nacional de Educação Especial: Equitativa, Inclusiva e com Aprendizado ao Longo da Vida. Disponível em: https://presrepublica.jusbrasil.com.br/legislacao/936694859/decreto10502-20 Acesso em: 05 jan. 2021.

CAROLEI, P; TORI, R. Gamificação aumentada explorando a realidade aumentada em atividades lúdicas de aprendizagem. Revista Digital de Tecnologias Cognitivas TECCOGS, n. 9, jan./ jun. 2014, p. 15-35.

CASAIS, J. A. C.; NETO, W. A. Contribuições da Semiótica para a Inclusão de Estudantes Autistas no Ensino de Ciências. In:ENCONTRO NACIONAL DE PESQUISA EM EDUCAÇÃO EM CIÊNCIAS, 10, 2015, Águas de Lindóia, SP. Anais [...]. Águas de Lindóia: ABRAPEC, p. 1-8.

COSTA, C. F.; MEDEIROS, D. O ensino de Ciências em um Contexto Inclusivo: relato de uma prática pedagógica no curso de Ciências Biológicas. Revista Insignare Scientia$R I S$; v.3 n.5, 18 de dez de 2020 .

COSTA, W. da S.; VIANA, B.; GOMES, S. Gamificação: uma estratégia para socializar o aluno autista de grau leve nas aulas de ciências. In: ENCONTRO NACIONAL DE PESQUISA EM EDUCAÇÃO EM CIÊNCIAS. 12, 2019, Natal, RN. Anais [...]. Natal: ABRAPEC, p. 1-9.

DELEUZE, G . Bergsonismo. Tradução de Luiz B. L. Orlandi.Rio de Janeiro: Ed. 34, 1999.

DELIGNY, F. Cartes Et Lignes D’Erre. França: L'arachneen, 2013. 
GERHARDT, T. E.; SILVEIRA, D. T. Métodos de Pesquisa. Rio Grande do Sul: UFRGS Editora, 2009.

GONÇALVES, N. T. L. P.; KAUARK, F. S.; NUNES FILHO, C. F. O Ensino de Ciências para autistas. Experiências em Ensino de Ciências, v.15, n.1, 2020.

LACERDA, L. Transtorno do Espectro Autista: uma brevíssima introdução. Curitiba: CRV, 2018.

MANTOAN, M. T. E. O direito de ser, sendo diferente na escola. In: RODRIGUES, D. (org.). Inclusão e educação: doze olhares sobre a educação inclusiva. São Paulo: Summus, 2005.

Manual diagnóstico e estatístico de transtornos mentais [recurso eletrônico]: DSM-5 / [American Psychiatric Association; tradução: Maria Inês Corrêa Nascimento ... et al.]; revisão técnica: Aristides Volpato Cordioli ... [et al.]. 5. ed. Porto Alegre: Artmed, 2014. 992 p.

MEDEIROS, D. Diferença e subjetividades do corpo: que educação é essa? 2012. Dissertação (Mestrado em Educação). Universidade Federal de Santa Maria, Santa Maria / RS, 2012.

PASSOS-BUENO, M. R.; VADASZ, E.; HUBNER, M. M. C. Um retrato do autismo no Brasil. [Depoimento a Carolina Oliveira]. Espaço Aberto. Comportamento, São Paulo, Coordenadoria de Comunicação Social - CCS/USP, n. 170, p. on-line, 2015. Disponível em: http://www.usp.br/espacoaberto/?matéria=um-retrato-do-autismo-nobrasil. Acesso em: 07 de janeiro de 2021.

PLANELLA, J. Fernand Deligny: pedagogía y nomadismo en la educación de las «otras infancias». Revista d'Història de l'Educació, 20, 2012, p. 95-115.

RAVET, J. But how do I teach them?: Autism \& Initial Teacher Education (ITE). International Journal of Inclusive Education, v.22, n7, 2017, p. 714-733.

RESENDE, N. C. Do asilo ao asilo, as existências de Fernand Deligny: trajetos de esquiva à Instituição, à Lei e ao Sujeito, 2016. Tese (Doutorado em Educação). Pontifícia Universidade Católica do Rio de Janeiro, Rio de Janeiro/RS, 2016.

SANTOS, K. S.; GALIETA, T. Ensino de Ciências e Educação Inclusiva: uma análise dos trabalhos apresentados no ENPEC. In: ENCONTRO NACIONAL DE PESQUISA EM EDUCAÇÃO EM CIÊNCIAS, 12, 2019, Natal, RN. Anais [...]. Natal: ABRAPEC, 2019, p. 1-6.

SASSAKI, R. K. Inclusão/Construindo uma sociedade para todos. Rio de Janeiro: WVA, 1997. 
SHAW, G.S.L. Relação entre família, escola, especialistas e o desenvolvimento de pessoas autistas. Perspectivas em Diálogo, Naviraí, v. 8, n. 16, p. 183-201, jan./abr. 2021. Disponível em: https://periodicos.ufms.br/index.php/persdia/index. Acesso: 11 de janeiro de 2021.

STEPANHA, K. A. O. A apropriação docente do conceito de autismo e o desenvolvimento das funções psicológicas superiores: uma análise na perspectiva da psicologia histórico-cultural. 2017. 167 f. Dissertação (Mestrado - Programa de PósGraduação em Educação) - Universidade Estadual do Oeste do Paraná, Cascavel, 2017.

TOLOMEI, B.V. A Gamificação como Estratégia de Engajamento e Motivação na Educação. EaD em Foco, 7 (2), 2017, p.145 -- 156.

XAVIER, M. F.; SILVA, B. Y. D.; RODRIGUES, P. A. Ensino de Ciências inclusivo para alunos com Transtorno do Espectro Autista e o uso de Sequências Didáticas. In: ENCONTRO NACIONAL DE PESQUISA EM EDUCAÇÃO EM CIÊNCIAS, 11, 2017, Florianópolis, SC. Anais [...]. Florianópolis: ABRAPEC, 2017, p. 1-8. 